This is the peer-reviewed version of the following article:

Stevanović, N. R.; Peruskovic, D. S.; Gašić, U. M.; Antunovic, V. R.; Lolić, A.; Baošić, R. Effect of Substituents on Prediction of TLC Retention of Tetradentate Schiff Bases and Their Copper(II) and Nickel(II) Complexes. Biomedical Chromatography 2017, 31 (3). https://doi.org/10.1002/bmc.3810

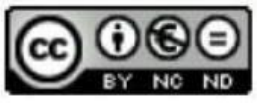

This work is licensed under a Creative Commons - Attribution-Noncommercial-No Derivative Works 3.0 Serbia 


\title{
Effect of substituents on prediction of TLC retention of tetra-dentate Schiff bases and their Copper(II) and Nickel(II) complexes
}

Nikola R.Stevanović ${ }^{1}$, Danica S.Perušković ${ }^{1}$, Uroš M.Gašić ${ }^{1}$, Vesna R.Antunović ${ }^{2}$, Aleksandar Đ.Lolić ${ }^{*}$, and Rada M.Baošić ${ }^{1}$

${ }^{1}$ Faculty of Chemistry, University of Belgrade, Studentski trg 12-16, Belgrade, Serbia

${ }^{2}$ Faculty of Medicine, University of Banja Luka, Save Mrkalja 14, 78000 Banja Luka, Bosnia and Herzegovina

*author for correspondence: phone: + 381113336 794, fax: + 381112184330

E-mail: 1olix@ @hem.bg.ac.rs

\begin{abstract}
The objectives of this study were to gain insights into the structure-retention relationships and to propose the model to estimating their retention. Chromatographic investigation of series of 36 Schiff bases and their Copper(II) and Nickel(II) complexes, was done under both normaland reverse-phase conditions. Chemical structures of the compounds have been characterized by molecular descriptors which are calculated from the structure and related to the chromatographic retention parameters by multiple linear regression analysis. Effects of chelation on retention parameters of investigated compounds, under normal- and reversephase chromatographic condition, were analyzed by PCA, QSRR and QSAR models were developed on the basis of theoretical molecular descriptors, calculated exclusively from molecular structure, and parameters of retention and lipophilicity.
\end{abstract}

\section{Keywords}

Schiff bases, TLC, PCA, QSRR, QSAR

This article has been accepted for publication and undergone full peer review but has not been through the copyediting, typesetting, pagination and proofreading process which may lead to differences between this version and the Version of Record. Please cite this article as doi: 10.1002/bmc.3810 


\section{Introduction}

Schiff bases are organic compounds that have broad use in biology, medicine and pharmacy. They are used as complexing agents as they form stable complexes with transition metals. Some of these complexes have antibiotic, antitumor and antiviral effect. The properties of complexe coordination center change accordingly to the present substituents (Bader, 2010; Raman et al., 2003; Naeimi and Nazifi, 2013; Abd-Elzaher, 2001; Khuhawar and Talpur, 1992; Calligaris, 1972).

Tetra-dentate Schiff bases are used for determination of metal ions by gas and liquid chromatography due to their selective reactions with them (Khuhawar and Soomro, 1992). Metal complexes are used as modified stationary phase in gas chromatography for separation of various compounds such as alcohols, ketones, aldehydes, esters, nitro- and amino compounds (Laghari et al., 2010). They can also be used for modification of stationary phases in HPLC separations of copper and nickel ions (Bader et al., 2012).

Retention in TLC is the result of competitive distribution of the investigated compounds between the mobile and stationary phase. The molecular structure and chemical properties of these compounds and applied chromatographic systems determine the type and extent of the interactions between them. The forces associated with these interactions may be related to the geometric, topological, and electric characteristics of the compounds, i.e. molecular descriptors.

Molecular descriptors are mathematical values that describe chemical structure of investigated compounds. They can be experimental and teorethical. Multivariant Linear Regression (MLR) correlate chromatographically determined retention parameter $\left(\mathrm{R}_{\mathrm{M}}\right)$ and molecular descriptors. MLR is statistical method where dependent variable Y and more than one independent variable $\mathrm{X}$, connected by the equation $\mathbf{Y}=\mathbf{X b}$ (capitals mean matrices, lower case means a vector). Principal Component Analysis (PCA) used as a method for classification (Hubert and Engelen, 2004; Kallitharka et al., 2001; Parineta et al., 2004). The basic idea of this statistical technique is to reduce the dimensions of the data obtained by experiments. All independent variables are projected in several principal components linearly combined with original variants and they describe the maximum of variance in the given data set (Escuder-Gilabert et al., 2005; Trifković et al., 2010; Kovačević et al., 2013). The QSRR 
(Quantitative Structure-Retention Relationship) describes the effect of chemical structure on the retention of investigated compounds. Whereas the QSAR (Quantitative Structure-Activity Relationship) shows their influence on the biological activity (e.g. lipophilicity) (Moustafa, 2008; Kiralj and Ferreira, 2009) as well as interaction between drug molecules and DNA (Abdel-Rahman et al., 2014; Abu-Dief and Nassr, 2015; Abdel-Rahman et al., 2016; AbdelRahman et al., 2016).

Our research group investigates tetra-dentate Schiff bases and their complexes with confirmed biological activity. Retention and lipophilicity of these compounds were investigated on several thin layers. Quantitative relation between structure, retention and activity/property as well as electrochemical behaviour and antioxidative activity of these compounds, were also investigated (Baošić and Tešić, 1995; Baošić et al., 2003; Baošić et al., 2008; Baošić et al., 2010; Aburas et al., 2012; Aburas et al., 2013). Results motivated us to examine the effect of structure of Schiff bases and their $\mathrm{Ni}(\mathrm{II})$ and $\mathrm{Cu}(\mathrm{II})$ complexes on chromatographic behaviour under normal and reverse-phase conditions in order to determine effect of substituent on retention.

In this paper we established QSAR and QSRR models for the same set of complexes under the same chromatographic conditions so we could easily compare them. With the QSRR and PCA results applied to the set of investigated compounds we could describe the effect of substituents on their chromatographic behavior, due to the fact that TLC presents model system for simulation of in vivo processes, such as passing of biologically active compounds through cell membrane. According to the results described in this paper the synthesis of new compounds with substituents that will enhance its lipophilic character is possible. 


\section{Material and methods}

\section{Investigated compounds}

Schiff bases which contain ethane-1,2-diamine or propane-1,2-diamine as the amine part and pentane-2,4-dione and/or 1-phenylbutane-1,3-dione, pentane-2,4-dione and/or 1,1,1trifluoropentane-2,4-dione, or 1,1,1-trifluoropentane-2,4-dione and/or 1-phenylbutane-1,3dione as beta-diketones part, were synthesized as describe in previous work (Baošić and Tešić, 1995). Their structures are presented in Table 1.

\section{Chromatography}

Chromatographic investigations were carried out by horizontal thin layer chromatography on silica gel RP-18 plates, $10 \times 10 \mathrm{~cm}$ (Merck, Darmstadt, Germany) using a Camag horizontal HPTLC development chamber in the tank configuration. Standard solutions $(5 \mathrm{mg} / \mathrm{mL})$ of the compounds were prepared in appropriate solvent. The plates were spotted with $1.0 \mu \mathrm{L}$ aliquots of freshly prepared solutions of the corresponding compound. Prior to the development, the spotted plates were equilibrated for 30 minutes in a chromatographic chamber saturated with mobile phase vapor. All solvents used throughout the present study were of analytical-grade purity. The applied mobile phases were mixtures of different organic modifiers and water. The list of applied mobile phases is presented in Table 2. Silica gel and reverse phase silica gel (RP-18) thin layer were used as stationary phases. The investigated compounds were chromatographed simultaneously. After development, the spots were colored by their own color. $\mathrm{R}_{\mathrm{F}}$ values were determined as averages from three independent measurements. All measurements were carried out at ambient temperature $\left(22 \pm 2{ }^{\circ} \mathrm{C}\right) . \mathrm{R}_{\mathrm{M}}$ values were calculated by use of the Bate-Smith and Westall equation (Bate-Smith and Westall, 1950). 


\section{Calculations}

All structures were drawn with the HyperChem Professional software (version 7.0, Hybercube, Gainseville, FL, USA). In order to obtain molecular descriptors, the geometry optimization of molecules was performed by the molecular mechanics MM+ force field method. The single-point calculation was done with the semi-empirical quantum chemical method ZINDO/1. Additional calculations of the molecular descriptors have been developed by Molecular Modelling Program Plus (MMP Plus) software (http://www.norgwyn.com/mmpplus.html). Following descriptors were calculated: Molecular Volume $(M V)$, Surface Area $(S A)$, Energy of the Highest Occupied Molecular Orbital $\left(E_{\text {Номо }}\right)$, Energy of the Lowest Unoccupied Molecular Orbital $\left(E_{L U M O}\right)$, Dipole Moment $(\mu)$, Refractivity $(R)$, Polarizability $(\alpha)$, Hydrophilic-Lipophilic Balance (HLB), and Lipophilicity Parameter $C \log P$. Statistical calculations, variable selection routine and multiple linear regression analysis (MLR) were performed by NCSS 2004 software package (Hintze, 2001). PCA has been performed using a demo version of PLS_Toolbox statistical package (Eigenvectors, v. 5.7) for MATLAB version 7.4.0.287 (R2007a) (MathWorks, Natick, MA, USA).

\section{Results and discussion}

\section{Thin layer chromatography}

Chromatographic investigation of the 36 compounds was performed by the normal and reverse-phase chromatography. Under normal-phase conditions the separation was carried out on silica gel with 11 mono-, 2 two-component aquaeous and 4 two-component nonaquaeous mobile phases. Reveresed-phase chromatography was done on silica gel RP-18 thin layer using 5 mono- and 7 two-component aqueous as well as 2 two-component nonaquaeous mobile phases (Table 2).

Investigated set of the Schiff bases and their $\mathrm{Cu}(\mathrm{II})$ and $\mathrm{Ni}(\mathrm{II})$ complexes represent suitable model systems for examination and correlation of the separation mechanisms in various chromatographic systems, primarily because of the presence of different substituents that can be successively introduced in their structure (Table 1). 


\section{Principal component analysis}

The major advantage of PCA application in chromatography is clustering of investigated compounds according to their retention behavior and in the possibility of linking this behavior with structural characteristics of the studied compounds. PC1 defines the freedom of variation in retention data, while PC2 defines the maximal deviation.

Similarities and dissimilarities between the investigated compounds and their retention were determined by PCA. Also, PCA was applied on calculated molecular descriptors and retention parameters of Schiff bases and their $\mathrm{Cu}(\mathrm{II})$ and $\mathrm{Ni}$ (II) complexes. The following systems were investigated: i) retention parameters obtained by normal-phase chromatography; ii) retention parameters obtained by reverse-phase chromatography; iii) classification of investigated compounds, based on calculated molecular descriptors (for both, Schiff bases and complexes- biplot).

\section{PCA for complexes}

Figure 1 shows results of PCA analysis for normal- and reverse-phase chromatography. PC1 (Figure 1a) recognizes differences between complexes with trifluoromethyl- and phenyl-group. However, PC1 does not separate complexes with different central ion or different diamine bridge. This is in accordance with mechanism of separation in terms of normal-phase chromatography. For example, PC1 separates complexes in pairs $(1,13),(2,14)(5,11)(4,10),(6,12),(7,13),(16,22)$ and $(17,23)$ regardless of the central metal ion or the diamine bridge. Also, the PCA reveals that complexes form three main separate clusters, which is in agreement with their structural characteristics and specific interactions in applied normal-phase chromatographic system. First cluster contains complexes with phenyland/or trifluoromethyl-group (3, 4, 9, 10, 16 and 22). Present substituents exhibit both, negative inductive and steric effect in applied chromatographic systems. The other two clusters contain complexes in which the asymmetry is present with regard to the substituents. Namely, they contain, on the one hand, methyl-group, while on the other, a phenyl- $(2,8,14$ and 20) or a trifluoromethyl-group (5,11, 17 and 23). Opposite, in terms of reverse-phase chromatography, PC1 (Figure 1b) separates complexes with phenyl- and trifluoromethylgroup in cluster $(3,4,9,10,15,16,21$ and 22), while PC2 poorly recognize similarities in structured of investigated compounds. 
On Figure 2 are shown biplot based on molecular descriptors for investigated complexes. PC1 separates $\mu$ and $E_{L U M O}$ from the others molecular descriptors. As can be seen from Figure 2, $E_{L U M O}$ recognizes the presence of methyl-group $(1,7,13$ and 19), while the molecular descriptor $\mu$ recognizes successive substitution of methyl- by trifluoromethylgroup $(5,6,11,12,17,18,23,24)$. $E_{L U M O}$ is decribed as possibility of the molecul to be good nucleophile, while dipole moment $(\mu)$ belongs to the group of "electric polarization descriptors" and gives insight in charge distribution within the molecule. On the other hand molecular descriptors $H L B, C \log P, S A$ and $M V$, distinguish the presence of trifluoromethyland phenyl-group $(4,10,16,22)$. $H L B$ presents molecular descriptor that shows if the investigated component has hydrophobic or hydrophillyc or both groups on its surface (Todeschini and Consonni, 2009).

Finally, $E_{\text {Номо }} \alpha$ and $R$ distinguish successive substitution of methyl- by phenyl- group (2, $3,8,9,14,15,20,21)$. The energy of the $E_{\text {Номо is directly related to the ionization potential }}$ and it decribes the possibility of molecule toward attack by electrophiles (Karelson and Lobanov, 1996).

\section{PCA of Schiff bases}

Dependence of PC1 and PC2 based on retention parameters $\mathrm{R}_{\mathrm{M}}$ of Schiff bases, obtained for normal- and reverse-phase chromatography (Figure 3a and 3b). PCA doesn't present satisfactory grouping of investigated compounds according to their structures in comparison with complexes (Figure 1). This is probably due to the open structure of the observed Schiff base compared with the closed system of complex compounds, which is square planar, i.e. is located in a single spatial plane. Distribution of investigated Schiff bases in terms of normalphase chromatography shows no noticeable regularity. Open system and long structure gives the possibility of spatial orientation of molecules, which allows hydrogen bonding interactions with the applied sorbent. However, the observed clustering of Schiff bases along the PC1 axis in terms of reverse-phase chromatography shows a clear tendency to clustering compounds in relation to the substituents present in order to favor hydrophobic interactions that dominate in this chromatographic system $(25,31 ; 26,32,29,35 ; 27,33,30,36$; and 28 , 34). 
Figure 4 shows biplot based on molecular descriptors of investigated Schiff bases. PC1 separates $H L B$ and $\alpha$, together with compounds with methyl- and/or trifluoromethylgroup, from others descriptors and compounds. This is in accordance with chromatographic behavior of compounds under normal- and reversed-phase conditions. Also, PC2 separates investigated compounds in relation to electronic or geometric descriptors.

Based on results it is obvious that substituents have an impact on chromatographic behavior of investigated compounds, e.g. their inductive and steric effect.

In normal-phase conditions, substitution of methyl- by trifluoromethyl- and/or phenylgroup reduced the electron density of donor atoms, due to change of inductive effect. The consequence of this effect is the increased mobility of the investigated compounds due to weaker hydrogen bonds. Trifluoromethyl- and phenyl-groups are voluminous and because of the steric effect they hinder access of donor atoms to silanol groups on sorbent surface. Also, compounds with propilenediamine in diamine bridge are more hydrophobic, in comparison to ethylenediamine. Accordingly they may form strong hydrogen bonds with silanol groups of silica-gel. Steric effect is not pronounced so oxygen and nitrogen donor atoms can easily approach the sorbents surface and silanol groups and interact with them. As expected, reverse-phase chromatography gave the reverse order of elution of the compounds. Under these conditions chromatographic behavior is based on the non-specific interactions of the aromatic rings of the compounds with the sorbent and the specific interactions with the mobile phase. Substitution of methyl- with trifluoromethyl- and/or phenyl-group leads to the increase of hydrophobicity of compounds. Application of reverse-phase chromatography gave better separation of investigated Schiff bases (25-36) with considerably more pronounced effect of substituents. Namely, the structure of Schiff bases contains large number of $\mathrm{sp}^{3}$ atoms. The effect of substituents introduced into Schiff base, decreases with the chain length which causes small differences in retention. The lipophilicity of the Schiff bases and their complexes increased with substitution of methyl-group by a more polar trifluoromethyl-group. Lipophilicity is affected by electron-withdrawing properties and strong resonance of trifluoromethyl- and phenyl-group. 


\section{QSRR}

The QSRR models were established for all applied stationary and mobile phases based on retention parameters $\left(\mathrm{R}_{\mathrm{M}}\right)$ for Schiff bases as well as their complexes. As a criterion for the quality check of QSRR models the following parameters were calculated: $\mathrm{r}^{2}$,correlation coefficient; MSE, Mean Square Error; F, Fischer statistical parameter; $\mathrm{r}_{\mathrm{cv}}{ }^{2}$, correlation coefficient for cross-referenced validation; PRESS, Predictive Residual Sum of Squares) and SSY, Sum of the Squared Deviations. The PRESS parameter clearly defines the error of the established model. The value of the ratio PRESS/SSY lower than 0.4 shows that the QSRR model is statistically validated as good, but if the value of the ratio is lower than 0.1 shows that the model is perfect (Van de Waterbeemd, 1995).

\section{Complexes}

Table 3 present the statistically best QSRR model for complexes. Under reversed-phase chromatographic condition, dominant mechanisms are hydrophobic interaction between sorbent and complexes. The delocalization of the $\pi$-electrons over the whole chelate ring is increased by substitution of methyl- with phenyl- and/or trifluoromethyl-group. The lipophilicity of the coordination compounds is enhanced with these substitutions. Model 1 shows that the highest impact on retention have these descriptors: $\mu, E_{\text {Номо }}$ and $C \log P$. The results indicated that lipophilic character is not only affected by the composition and structure of the molecule and that some other interactions could be important. This is in accordance with expected chromatographic behavior of these compounds as well as results of biplot by PCA. Based on PRESS/SSY ratio model 1 (Table 3) belongs to the group of perfect models.

\section{Schiff bases}

Model 2 (Table 3) represents statistically the best model for Schiff bases. In this model the highest impact on the retention, have: $\alpha, E_{\text {Номо }}, \mu, M V$ and $C \log P$.

Under applied reversed-phase chromatographic conditions, Clog $P$ is the most influencing parameter due to dominant hydrophobic interactions. Also, $\alpha$ and $M V$ have the lowest influence. In this case the molecular size has no effect, because all ligands are in the open form. 


\section{QSRR/QSAR for complexes}

In previous paper (R. Baošić et al., 2008) the biological activity of investigated complexes of Copper(II) and Nickel(II) was described. Based on that finding we wanted to compare established QSRR and QSAR models for investigated complexes. For this purpose we have chosen statistically best QSRR model, whose $\mathrm{R}_{M}$ values were obtained by reversedphase chromatography, because the lipophilicity parameters in QSAR model, were obtained under the same condition. QSAR model is present in Table 3 (model 3). Under the same conditions, this model is statistically less credible than QSRR (Table 3, model 1).

The lipophilicity has a significant impact on biological activity based on absorption, distribution, metabolism, and excretion of compounds (ADME properties). Lipophilicity of Copper(II) and Nickel(II) complexes strongly depends on substitution of methyl- by trifluoromethyl- and/or phenyl-group. The chelation changes the characteristics of Schiff bases as ligands. This process has influence in behavior of observed complexes in reversedphase chromatographic systems, as well as in biological systems. The chelation of Schiff base reduces the polarity and increases the lipophilic nature of the complexes. Therefore, the complexes shown enhanced activity as compared to parent ligand.

From these established models we can assume that $R_{M}$ parameter is better than $R_{M}{ }^{0}$ for describing lipophilicity of Schiff base complexes and structurally similar compounds, in vivo (Perušković et al., 2014).

\section{Conclusions}

The QSRR models describe relations between the molecular properties of observed set of Schiff bases and corresponding $\mathrm{Cu}(\mathrm{II})$ and $\mathrm{Ni}(\mathrm{II})$ complexes, and their chromatographically obtained retention parameters. Effects of substitution, inductive and steric effect on retention parameters of investigated compounds, under normal- and reverse-phase chromatographic condition, were analyzed by PCA. For investigated complexes, $E_{L U M O}$ recognizes the presence of methyl-group, while the molecular descriptor $\mu$ recognizes successive substitution of methyl- by trifluoromethyl-group. Molecular descriptors $H L B, C \log P, S A$ and $M V$, distinguish the presence of trifluoromethyl- and phenyl-group. Also, $E_{\text {Номо }} \alpha$ and $R$ distinguish successive substitution of methyl- by phenyl-group. For investigated Schiff bases, $H L B$ and $\alpha$ recognizes compounds with methyl- and/or trifluoromethyl-groups. According to these results, the desire molecule should have voluminous substituents with enhanced 
inductive effect. It is also better that diamine bridge has propylene group due to higher hydrophobicity.

QSRR and QSAR models for investigated complexes were developed on the basis of theoretical molecular descriptors, calculated exclusively from molecular structure, and parameters of retention and lipophilicity. Lipophilicity of these compounds, in vivo, is better described by $R_{M}$ than $R_{M}{ }^{0}$ parameter, which is not in accordance with expected results.

\section{Acknowledgements}

This work was performed within the framework of the research project No 172017 supported by the Ministry of Education and Science of Serbia.

\section{References}

Abd-Elzaher MM. Spectroscopic Characterization of Some Tetradentate Schiff Bases and Their Complexes with Nickel, Copper and Zinc. Journal of the Chinese Chemical Society 2001; 48: 153-158.

Abdel-Rahman LH, El-Khatib RM, Nassr LAE, Abu-Dief AM, Ismael M and Seleem AA. Metal based pharmacologically active agents: Synthesis, structural characterization, molecular modeling, CT-DNA binding studies and in vitro antimicrobial screening of iron(II) bromosalicylidene amino acid chelates. Spectrochimica Acta 2014; 117: 366-378.

Abdel-Rahman LH, Abu-Dief AM, Ismael MM, Mohamed AA and Hashem NA. Synthesis, Structure Elucidation, Biological Screening, Molecular Modeling and DNA binding of Some $\mathrm{Cu}$ (II) Chelates incorporating Imines Derived from Amino Acids. The Journal of Molecular Structure 2016; 1103: 232-244.

Abdel-Rahman LH, Abu-Dief AM, Newair EF and Hamdan SK. Some new nano-sized $\mathrm{Cr}(\mathrm{III}), \quad \mathrm{Fe}(\mathrm{II}), \quad \mathrm{Co}(\mathrm{II}), \quad$ and $\mathrm{Ni}(\mathrm{II}) \quad$ complexes incorporating 2-((E)-(pyridine-2ylimino)methyl)napthalen-1-ol ligand: Structural characterization, electrochemical, antioxidant, antimicrobial, antiviral assessment and DNA interaction. The Journal of Photochemistry and Photobiology B: Biology 2016; 160: 18-31.

Abu-Dief AM and Nassr LAE. Tailoring, physicochemical characterization, antibacterial and DNA binding mode studies of $\mathrm{Cu}$ (II) Schiff bases amino acid bioactive agents incorporating 5-bromo-2-hydroxybenzaldehyde. Journal of the Iranian Chemical Society 2015; 12: 943-955. 
Aburas N, Lolić A, Stevanović N, Tripković T, Nikolić Mandić S and Baošić R. Electrochemical behavior and antioxidant activity of tetradentate Schiff bases and their Copper (II) complexes. Journal of Iranian Chemical Society 2012; 9(6): 859-864.

Aburas N, Stevanović N, Milčić M, Lolić A, Natić M, Tešić Ž and Baošić R. Influence of structure on antioxidant activity of tetradentat Schiff bases and their Copper(II) complexes: Possible mechanisms. Journal of the Brazilian Chemical Society 2013; 24(8): 1322-1328.

Bader N, Hutta M and Kuss HM. Selective separation of trace amount of copper(II), Manganese(II), Cadmium(II), and Nickel(II) ions with tetradentate Schiff base ligand by reversed-phase high performance liquid chromatography and spectrophotometric detection, Der Pharmacia Sinica 2012; 3(6): 715-718.

Bader NR. Applications of Schiff bases chelates in quantitative analysis: a review. Rasayan Journal of Chemistry 2010; 3(4): 660-670.

Baošić R, Milojković-Opsenica D and Tešić Ž. The effect of substituents in $\beta$ ketoiminatoligand of copper(II) and nickel(II) complexes on their retention on polyacrylonitrile thin layer. Journal of Planar Chromatography-Modern TLC 2003; 16: 412416.

Baošić R, Radojević A, Radulović M, Miletić S, Natić M and Tešić Ž. Relationships between structure, retention and biological activity of some Schiff base ligands and their complexes. Biomedical Chromatography 2008; 22: 379-386.

Baošić R, Radojević A, Tripković T, Aburas N and Tešić Ž. Quantitative Retention-Property Relationships Studies of some Schiff Base Ligands and their Complexes. Chromatographia 2010; 72(5): 545-549.

Baošić RM and Tešić ŽLj. The effect of $\beta$-ketoiminato ligand substituents of copper(II) and nickel(II) complexes on $\mathrm{R}_{\mathrm{F}}$ values obtained by thin-layer chromatography on silica gel. Journal of the Serbian Chemical Society 1995; 60(10): 903-908.

Bate-Smith EC and Westall RG. RPTLC determination of the lipophilicity of 1,2benzisothiazol-3(2H)-one derivatives substituted in the heterocyclic ring. Biochimica et Biophysica Acta 1950; 4: 427-440.

Calligaris M, Nardin G and Randaccio L. Structural aspects of metal complexes with some tetradentate Schiff bases. Coordination Chemistry Reviews 1972; 7: 385-403.

Escuder-Gilabert L, Sagrado S, Villanueva-Camañas RM and Medina-Hernández MJ. Quantitative structure-retention relationships for ionic and non-ionic compounds in biopartitioning micellar chromatography. Biomedical Chromatography 2005; 19: 155-168. 
Hintze J. NCSS and PASS (2001) Number Cruncher Statistical Systems. Kaysville. WwW.ncss.com

http://www.norgwyn.com/mmpplus.html

Hubert M and Engelen S. Robust PCA and classification in biosciences. Bioinformatics 2004; 20(11): 1728-1736.

Kallitharka S, Arvanitoyannis IS, Kefalas P, El-Zajouli A, Soufleros E and Psarra E. Instrumental and sensory analysis of Greek wines; implementation of principal component analysis (PCA) for classification according geographical origin. Food Chemistry 2001; 73: 501-514.

Karelson M and Lobanov VS. Quantum-Chemical Descriptors in QSAR/QSPR Studies. Chemical Reviews 1996; 96: 1027-1043.

Khuhawar MY and Soomro AI. Liquid and gas chromatographic procedures for the simultaneous determination of Copper, Nickel and Palladimu using tetradentate Schiff bases as complexing agents. Analytica Chimica Acta 1992; 268: 49-53.

Khuhawar MY and Talpur AK. Chromatographic separation of Copper(II), Nickel(II) and Palladium (II) Chelates of Tetradentate Schiff Bases Derived from 5-Methylhexane- 2,4dione and 1,1,1-Trifluoro-5-Methylhexane-2,4-dione. Journal of the Chemical Society of Pakistan 1992; 14(2): 102-108.

Kiralj R and Ferreira MMC. Basic Validation Procedures for Regression Models in QSAR and QSPR Studies: Theory and Application. Journal of the Brazilian Chemical Society 2009; 20(4): 770-787.

Kovačević SZ, Jevrić LR, Podunavac Kuzmanović SO and Lončar ES. Structure-retention relationship study of arylpiperazines by linear multivariate Modeling. Central European Journal of Chemistry 2013; 11(12): 2031-2039.

Laghari AJ, Khuhawar MY, Zeenat MA and Zardar LA. Bis(isovalerylacetone). Chromatographic Science 2010; 48: 303-309.

ethylenediimine Nickel(II) as Mixed Stationary Phase for Gas Chromatography, Journal of Moustafa NE. Prediction of GC Retention Times of Complex Petroleum Fractions Based on Quantitative Structure-Retention Relationships. Chromatographia 2008; 67: 85-91.

Naeimi H and Nazifi ZS. Convenient and mild synthesis and characterisation of some new Schiff bases, Short Communication. Bulletin of the Chemical Society of Ethiopia 2013; 27(1): 143-149. 
Parineta B, Lhotea A and Legubea B. Principal component analysis: an appropriate tool for water quality evaluation and management-application to a tropical lake system. Ecological Modelling 2004; 178: 295-311.

Perušković DS, Stevanović NR, Lolić AD and Baošić RM. Letters in Drug Design \& Discovery, 2014, 11(2): 162-168.

Raman N, Kulandaisamy A and Thangaraja C. Redox and antimicrobial studies of transition metal (II) tetradentate Schiff base complexes. Transition Metal Chemistry 2003; 28: 29-36.

Todeschini R, Consonni V. Molecular Descriptors for Chemoinformatics, Wiley-VCH, 2009; 137.

Trifković J, Andrić F, Ristivojević P, Andrić D, Tešić ŽLj and Milojković-Opsenica DM. Structure-retention relationship study of arylpiperazines by linear multivariate Modeling. Journal of Separation Science 2010; 33: 2619-2628.

Van de Waterbeemd H. Chemometric Methods in Molecular Design, Wiley-VCH, Weinheim, 1995. 
Table 1. Stuctures of investigated compounds

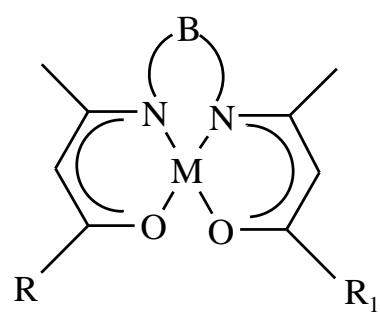<smiles>[R]C(=O)/C=C(\C)NPN/C(C)=C/C([Z1])=O</smiles>

$\begin{array}{lllllll}\text { Compound } & \text { Complex } & \mathrm{R} & \mathrm{R}_{1} & \mathrm{~B} & \text { Compound } & \text { Schiff bases }\end{array}$
(1) (13) $\left[\mathrm{M}\left(a c a c_{2} \text { en }\right)\right]^{a, b}$
$\begin{array}{lll}\mathrm{CH}_{3} & \mathrm{CH}_{3} & \mathrm{CH}_{2} \mathrm{CH}_{2}\end{array}$
(25) $\quad \mathrm{H}_{2}\left(a c a c_{2}\right.$ en $)$
(2) (14) $\quad[\mathrm{M}(\text { acac phacac en })]^{c}$
$\begin{array}{lll}\mathrm{CH}_{3} & \mathrm{C}_{6} \mathrm{H}_{5} & \mathrm{CH}_{2} \mathrm{CH}_{2}\end{array}$
(26) $\mathrm{H}_{2}$ (acac phacac en)
(3) (15) $\quad\left[\mathrm{M}\left(\right.\right.$ phacac $_{2}$ en $\left.)\right]$
$\mathrm{C}_{6} \mathrm{H}_{5} \quad \mathrm{C}_{6} \mathrm{H}_{5} \quad \mathrm{CH}_{2} \mathrm{CH}_{2}$
(27)
$\mathrm{H}_{2}\left(\right.$ phacac $_{2}$ en)
(4) (16) $\quad[\mathrm{M}$ (phacac tfacac en $)]^{d} \quad \mathrm{C}_{6} \mathrm{H}_{5} \quad \mathrm{CF}_{3} \quad \mathrm{CH}_{2} \mathrm{CH}_{2}$
(28) $\mathrm{H}_{2}$ (phacac tfacac en)
(5) (17) $\quad[\mathrm{M}($ acac tfacac en $)]$
$\mathrm{CH}_{3} \quad \mathrm{CF}_{3} \quad \mathrm{CH}_{2} \mathrm{CH}_{2}$
(29)
(6) (18) $\quad\left[\mathrm{M}\left(\mathrm{tfacac}_{2} \mathrm{en}\right)\right]$

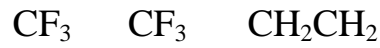
(30)
$\mathrm{H}_{2}$ (acac tfacac en)
(7) (19) $\quad\left[\mathrm{M}\left(a c a c_{2} \mathrm{pn}\right)\right]^{e}$
$\mathrm{CH}_{3} \quad \mathrm{CH}_{3} \quad \mathrm{CH}\left(\mathrm{CH}_{3}\right) \mathrm{CH}_{2}$
(31)
$\mathrm{H}_{2}\left(\right.$ tfacac $_{2}$ en $)$
(8) (20) [M(acac phacac pn)]
$\mathrm{CH}_{3} \quad \mathrm{C}_{6} \mathrm{H}_{5} \quad \mathrm{CH}\left(\mathrm{CH}_{3}\right) \mathrm{CH}_{2}$
(32)
$\mathrm{H}_{2}\left(\operatorname{acac}_{2} \mathrm{pn}\right)$
(9) (21) [M( phacac $\left.\left._{2} \mathrm{pn}\right)\right]$
$\mathrm{C}_{6} \mathrm{H}_{5} \quad \mathrm{C}_{6} \mathrm{H}_{5} \quad \mathrm{CH}\left(\mathrm{CH}_{3}\right) \mathrm{CH}_{2}$
(33)
$\mathrm{H}_{2}$ (acac phacac pn)
(10) (22) [M(phacac tfacac pn)]
$\mathrm{C}_{6} \mathrm{H}_{5} \quad \mathrm{CF}_{3} \quad \mathrm{CH}\left(\mathrm{CH}_{3}\right) \mathrm{CH}_{2}$
(34)
$\mathrm{H}_{2}$ (phacac 2 pn)
(11) $(23$
[M(acac tfacac pn)]
$\mathrm{CH}_{3} \quad \mathrm{CF}_{3} \quad \mathrm{CH}\left(\mathrm{CH}_{3}\right) \mathrm{CH}_{2}$
(35)
$\mathrm{H}_{2}$ (phacac tfacac $\mathrm{pn}$ )
(12) (24) $\left[\mathrm{M}\left(\mathrm{tfacac}_{2} \mathrm{pn}\right)\right]$
$\mathrm{CF}_{3} \quad \mathrm{CF}_{3} \quad \mathrm{CH}\left(\mathrm{CH}_{3}\right) \mathrm{CH}_{2}$
(36) $\mathrm{H}_{2}\left(t_{f a c a c} \mathrm{pn}\right)$

${ }^{a}$ acac $=$ pentane-2,4-dione; en $=$ ethane-1,2-diamine;

${ }^{b} \mathrm{M}=\mathrm{Cu}$ (II) (1-12) or $\mathrm{Ni}$ (II) (13-24)

${ }^{c}$ phacac $=1$-phenylbutane-1,3-dione;

${ }^{d}$ tfacac $=1,1,1$-trifluoropentan-2,4-dione;

${ }^{e} \mathrm{pn}=$ propane-1,2-diamine. 
Table 2. List of applied mobile phases

\begin{tabular}{|c|c|c|}
\hline No & Composition & Proportions $(\mathrm{v} / \mathrm{v})$ \\
\hline 1 & Chloroform & \\
\hline 2 & Acetone & \\
\hline 3 & Methanol & \\
\hline 4 & Ethanol & \\
\hline 5 & Dichlorometane & \\
\hline 6 & Carbon tetrachloride & \\
\hline 7 & Acetonitrile & \\
\hline 8 & 1,2,3,4-tetrahydronaphtalene & \\
\hline 9 & Amyl acetate & \\
\hline 10 & Dioxane & \\
\hline 11 & Tetrahydrofurane & \\
\hline 12 & Methanol-water & $80: 20$ \\
\hline 13 & Dioxane-water & $80: 20$ \\
\hline 14 & Tetrahydrofurane-water & $60: 40$ \\
\hline 15 & Ethanol-water & $70: 30$ \\
\hline 16 & Acetonitrile-water & $70: 30$ \\
\hline 17 & Isopropyl acetate-water & $70: 30$ \\
\hline 18 & Acetone-water & $70: 30$ \\
\hline 19 & Dichloromethane-carbon tetrachloride & $80: 20$ \\
\hline 20 & Toluene-dioxane & $60: 40$ \\
\hline 21 & Toluene-dioxane & $70: 30$ \\
\hline 22 & Methanol-carbon tetrachloride & $60: 40$ \\
\hline
\end{tabular}


Table 3. QSRR models for complexes and Schiff bases

\begin{tabular}{|c|c|c|c|c|c|}
\hline \multicolumn{3}{|c|}{ Equation } & \multirow[t]{2}{*}{$\mathrm{r}^{2}$} & \multirow[t]{2}{*}{ MSE } & \multirow[t]{2}{*}{$\mathrm{F}$} \\
\hline$r_{C V}^{2}$ & PRESS & PRESS/SSY & & & \\
\hline $\mathbf{1}^{\mathrm{a}}$ & \multicolumn{2}{|c|}{$\mathrm{R}_{\mathrm{M}}=1.871( \pm 0.108)+0.039( \pm 0.011) \cdot E_{\text {НОМО }}-0.044( \pm 0.008) \cdot \mu-$} & 0.945 & 0.014 & 113.362 \\
\hline \multirow[t]{2}{*}{0.920} & 0.401 & 0.080 & & & \\
\hline & & $0.331( \pm 0.021) \cdot C \log P$ & & & \\
\hline $2^{b}$ & \multicolumn{2}{|c|}{$\mathrm{R}_{\mathrm{M}}=29.600( \pm 10.071)-0.553( \pm 0.406) \cdot E_{\text {НОМО }}+0.192( \pm 0.069) \cdot \mu+$} & 0.959 & 0.012 & 27.785 \\
\hline \multirow[t]{2}{*}{0.802} & 0.347 & 0.198 & & & \\
\hline & \multicolumn{2}{|c|}{$1.311( \pm 0.461) \cdot \alpha+0.148( \pm 0.058) \cdot M V-3.651( \pm 1.309) \cdot C \log P$} & & & \\
\hline $3^{\mathrm{a}}$ & \multicolumn{2}{|c|}{$\mathrm{R}_{\mathrm{M}}^{0}=1.482( \pm 1.205)-0.571( \pm 0.166) \cdot E_{L U M O}+0.119( \pm 0.010) \cdot H L B+$} & 0.924 & 0.067 & 80.583 \\
\hline \multirow[t]{2}{*}{0.880} & 2.085 & 0.120 & & & \\
\hline & & $0.050( \pm 0.003) \cdot R$ & & & \\
\hline
\end{tabular}

$E_{\text {HOMO }^{-}}$Energy of the highest occupied molecular orbital; $\mu$-Dipole moment; $C \log P$-Lipophilicity parameter; $M V$ Molecular volume; $\alpha$-Polarizability; ELUMO-Energy of the Lowest Unoccupied Molecular Orbital ; $H L B$ -

Hydrophilic-Lipophilic Balance; R-Refractivity;

a) RP-18, dichloromethane-carbon tetrachloride (80:20)

b) RP-18, dichloromethane 

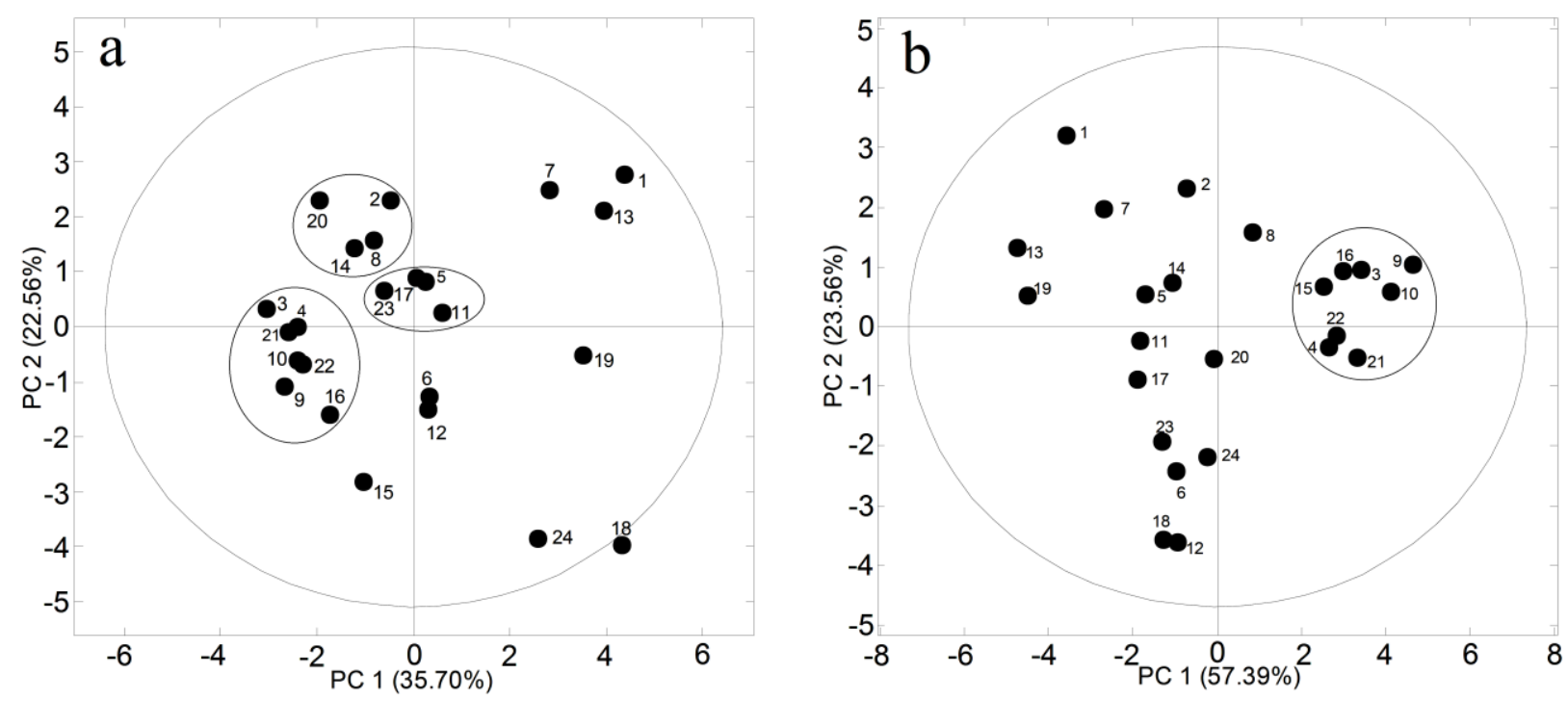

Figure 1. PCA for complexes based on $\mathrm{R}_{M}$ values: (a) silica gel; b) silica gel RP-18. 

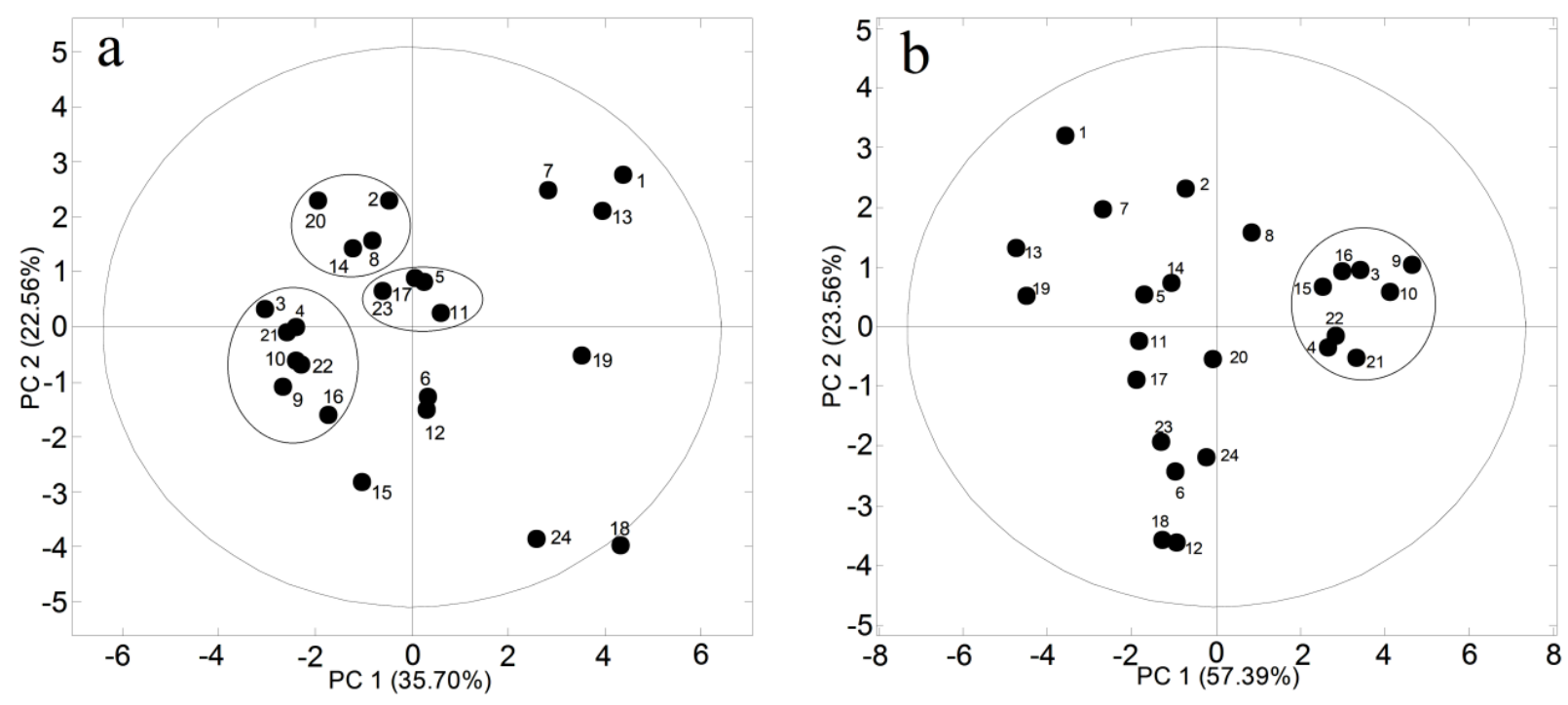

Figure 2. PCA of complexes based on molecular descriptors (biplot). 

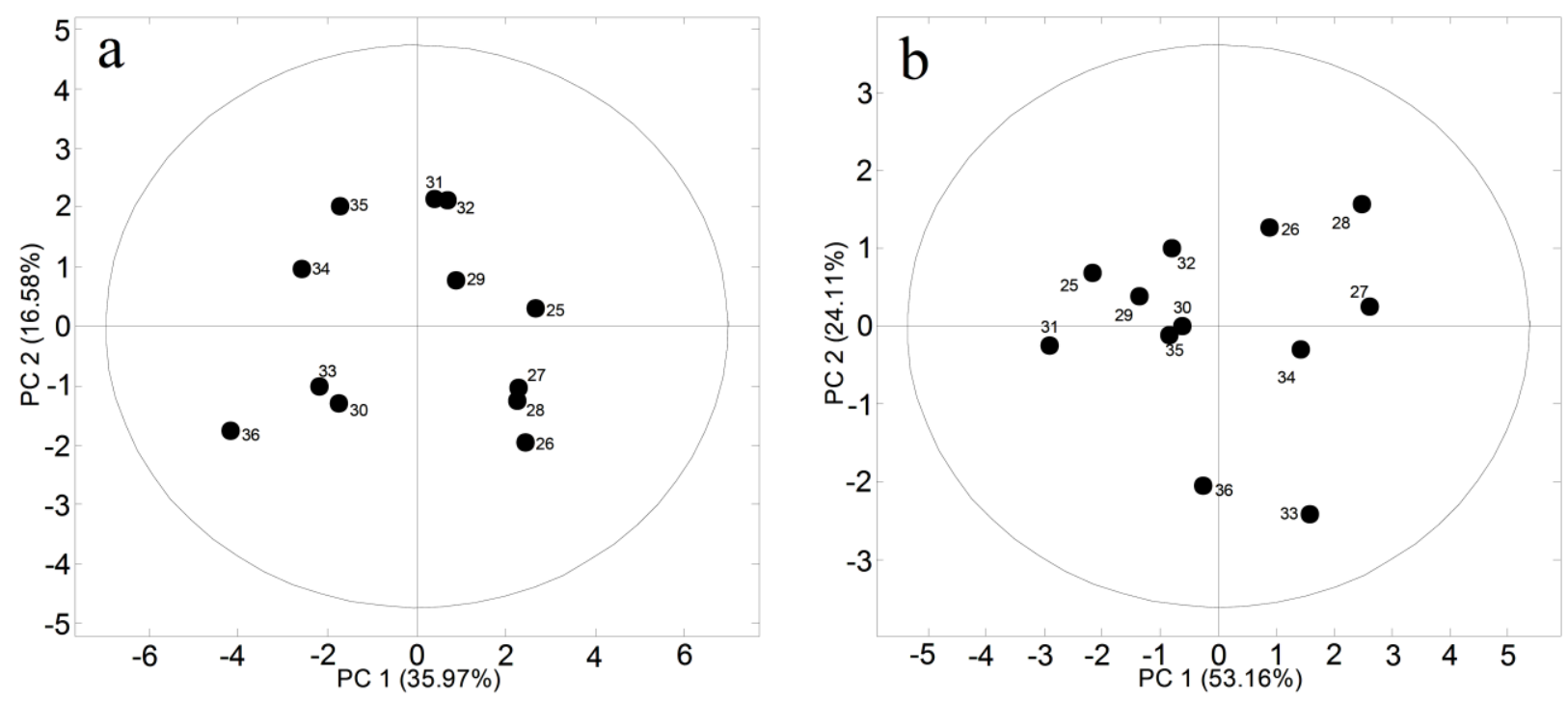

Figure 3. PCA for Schiff bases based on $\mathrm{R}_{M}$ values: (a) silica gel; b) silica gel RP-18. 


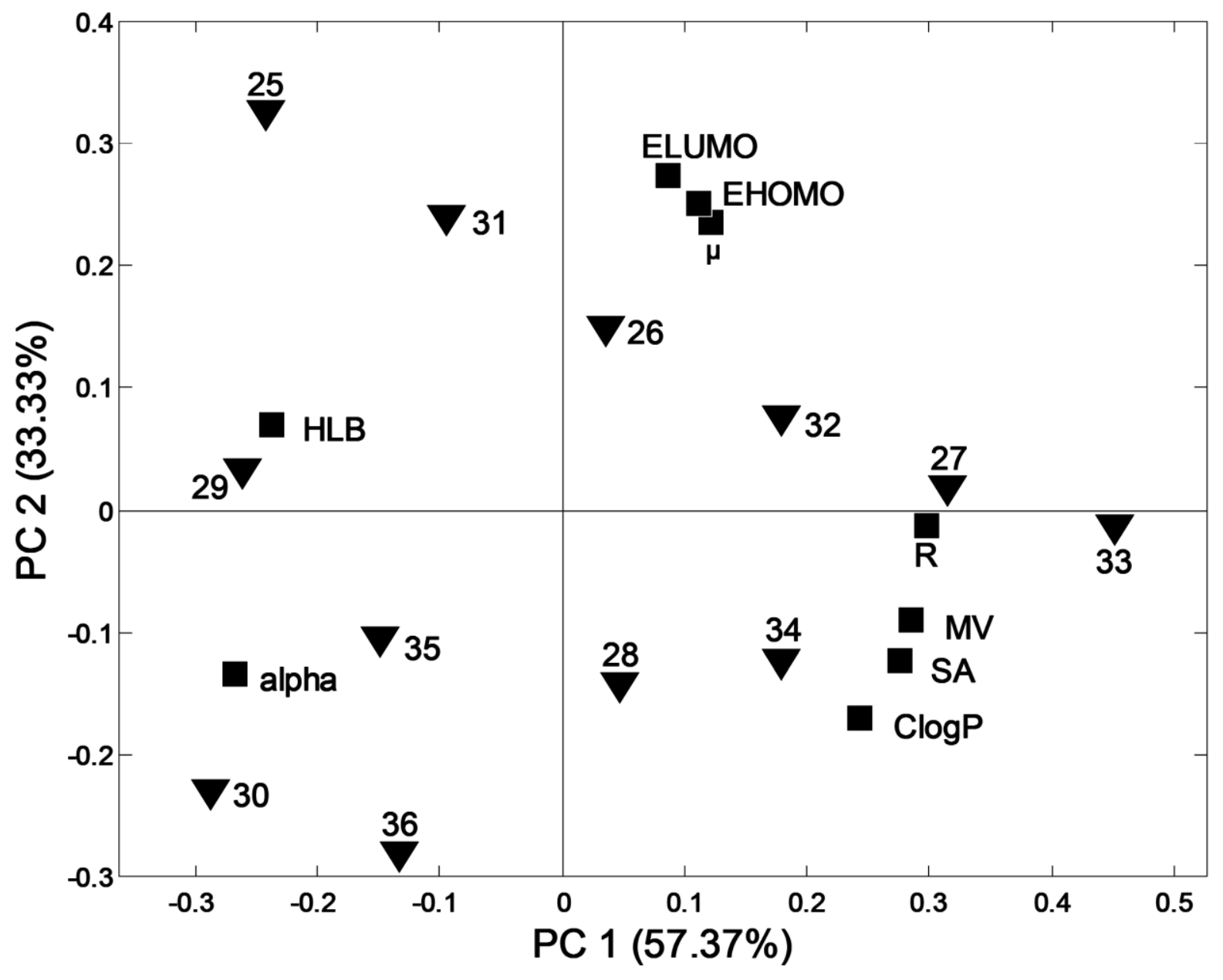

Figure 4. PCA of Schiff bases based on molecular descriptors (biplot). 